Lessons from an evaluation of a domestic well-being indicator system. N.M.Gil, Proc. $10^{\text {th }}$ International ACM SIGACCESS Conference on Computers and Accessibility (ASSETS 2008), Halifax, Nova Scotia, Canada, 13 - 15 Oct. 2008, pp.309-310. DOI: 10.1145/1414471.1414553

\title{
Lessons from an Evaluation of a Domestic Well-being Indicator System
}

\author{
Nubia M. Gil \\ (Supervisors: N.A. Hine and J.L. Arnott) \\ School of Computing, University of Dundee, Dundee DD1 4HN, United Kingdom.
}

This is a pre-print report of research published in:

Proceedings of $10^{\text {th }}$ ACM SIGACCESS Conf. on Computers \& Accessibility (ASSETS 2008)

Halifax, Nova Scotia, Canada, $13^{\text {th }}-15^{\text {th }}$ October 2008, pp.309-310.

ISBN: 978-1-59593-976-0

DOI: $10.1145 / 1414471.1414553$

URL: DOI Bookmark for the article: http://doi.acm.org/10.1145/1414471.1414553

Abstract: The objective of this study was to find out whether a domestic well-being indicator system might support the dialogue of care between the older person and his or her carer. Ten evaluation sessions, each one with three parts, were run with ten older people and ten carers. Peoples' attitudes and feelings, perceptions, and preferences were compared. Both qualitative and quantitative data were collected. In conclusion, the prototype could be used as a tool to improve the dialogue of care between the older person and the carer.

Keywords: Older adults, older people, user interfaces, evaluation, well-being.

Contact Address: N.Gil / N.Hine / J.Arnott,

School of Computing, University of Dundee,

Dundee DD1 4HN, United Kingdom.

\{nubiagil / nhine / jarnott\} at computing.dundee.ac.uk 


\section{INTRODUCTION}

A domestic well-being indicator system was designed and developed to present data collected from sensors installed in the homes of older people. The prototype has two user interfaces: one for the older person and one for the carer. The principal question was to find out if the prototype could be used as a tool to enrich the dialogue of care between the older person and the carer.

Researchers around the world have conducted various telecare projects that aimed to support the independence and autonomy of older people [1-3]. However, one aspect in the evaluation of telecare projects that has not been studied is the added value of technology in the dialogue of care between the older person and the carer. To enable this dialogue to take place graphical and textual data were used to inform changes of well-being indicators such as mobility, sleeping, eating and drinking, personal hygiene and medical conditions of the older people at home.

\section{METHODS}

\section{Participant Profiles}

Twenty people were recruited in person, by phone and by post. There were ten older people aged between 60 and 80 years and ten carers ( 3 physiotherapists, 2 occupational therapists, 2 scheme managers, 2 wardens and 1 social worker). The participants had different levels of computer skills: basic, intermediate and advanced. Some of them were not used to interpreting graphs.

\section{Methodology}

Ten sessions were run, each with one older person and one carer. Each session had three parts: the first part was individual, the second in pairs and the third one was a semi-structured interview with both participants and a facilitator. While users were performing their tasks, an observer took notes, and each session was video recorded. At the start of each session, the facilitator demonstrated how the prototype worked. Written instructions were distributed as well as an informed consent form.

A real scenario that described a diabetic person who had two changes in medication was given to the participants. Each participant had a different user computer interface (see figure 1 and 2), set of tasks and questions during the first part. They were asked to explore the software for 5 minutes, and to verbalise their thoughts while carrying out the list of tasks for 45 minutes, which consisted in checking the mobility, sleeping, eating and drinking, personal hygiene and medical conditions of an older person. In addition, the carers were requested to compare changes in the graphs before and after the medication event.

During the second part of the session, the older person and the carer worked together using either the older person's interface or the carer's interface for 45 minutes. The set of tasks was slightly different from the individual exercise because they were requested to discuss, check and compare changes in the graphs between days, weeks and months.

At the end of the second part the facilitator conducted a semi-structured interview to address the main issues raised by the participants such as attitudes and feelings, perceptions of both exercises, and preferences. Specific, open and closed questions were used to evaluate the prototype individually and in pairs. Closed questions were evaluated using a 5-point Likert scale ( $1=$ very low, 5=very high). Measures such as intuitiveness and self-explanation, usefulness and learnability were made. 
Gil: Lessons from an evaluation of a domestic well-being indicator system.

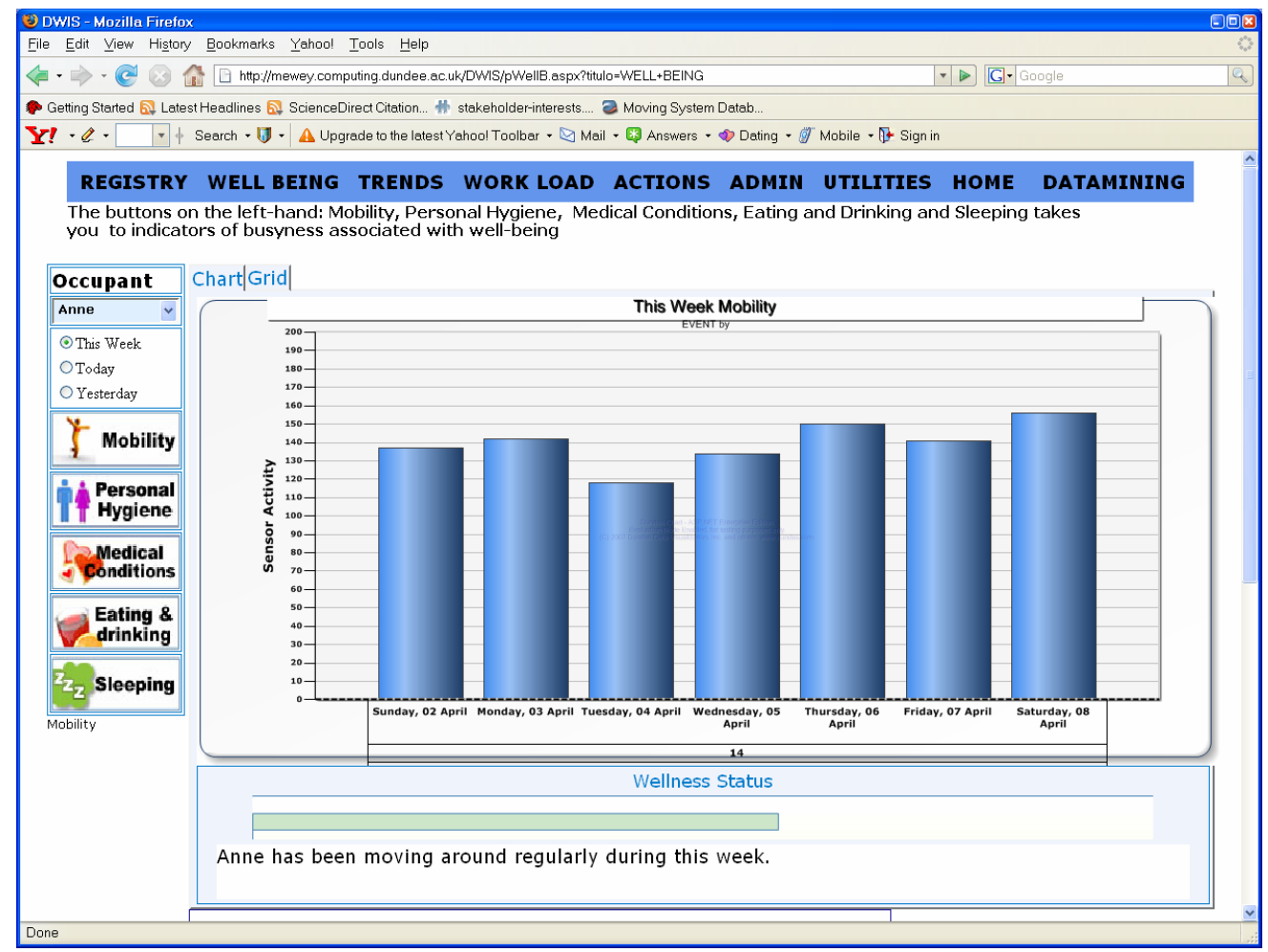

Figure 1. User computer interface for older people

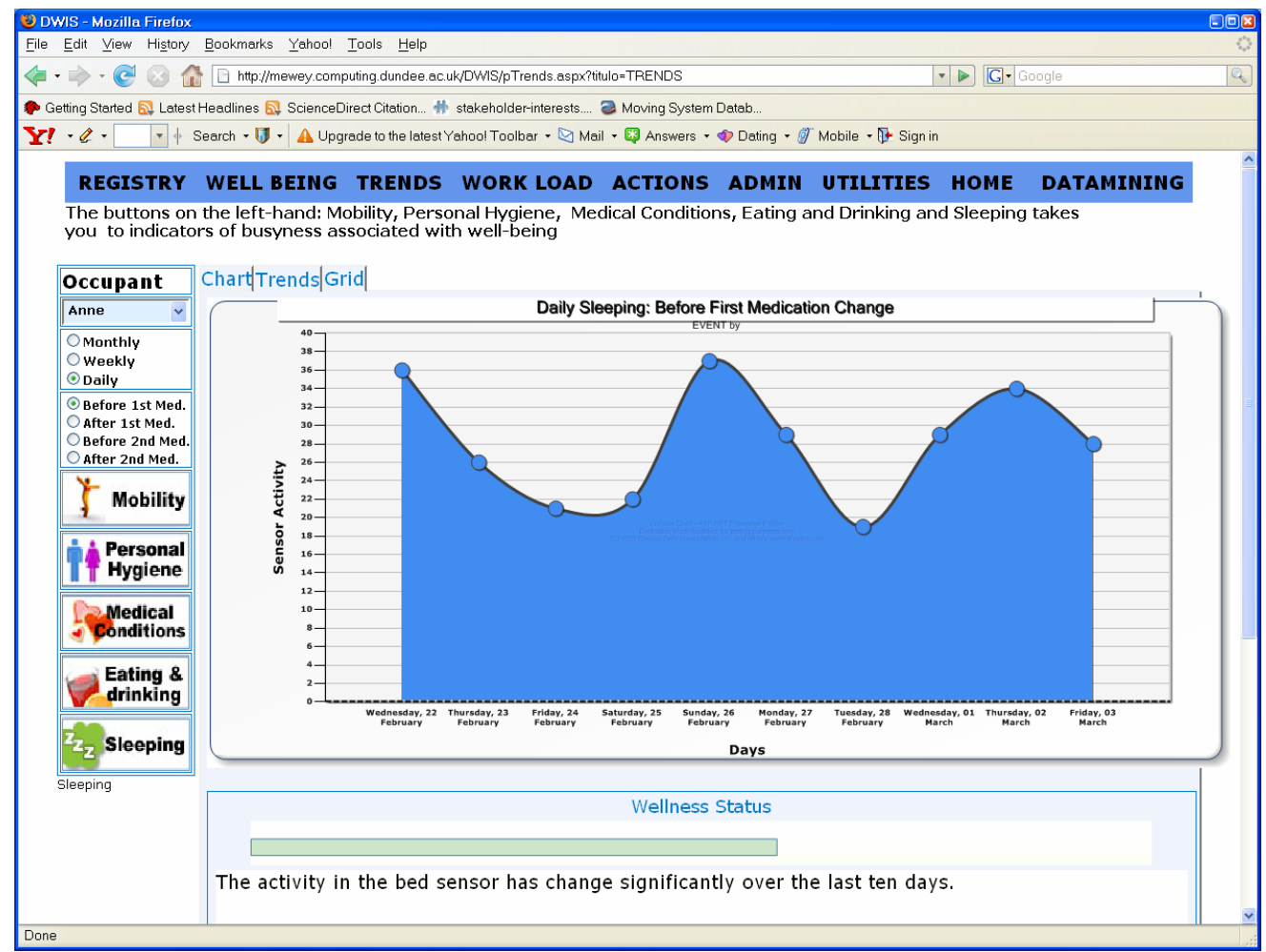

Figure 2. User computer interface for carers 


\section{RESULTS}

The collected data were coded using $\mathrm{NVivo}^{\circledR}$ and analysed based on: the stakeholder group (older person and carer); the ability to read graphs; user computer skills; confidence with technology and the modality of the exercise (individual and in pairs).

The following themes emerged using grounded theory [4]:

- Familiarity: some older people and carers felt unconfident, nervous and anxious at the beginning of the session. After they became familiar with the prototype they were more relaxed.

- Data presentation: both the older person's and the carer's interfaces had buttons with text and image, a graph and a statement about the graph (see figures 1 and 2). All participants liked the buttons as the image helped them to remember the meaning of the option. Most said that graphs were clear, visual and easy to read. Some wanted to know the normal range of the level of activity shown in the graph. Some liked the statement but others disliked it.

\section{Individual exercise}

Intuitiveness and self-explanation: some participants with basic computer skills had problems in understanding the graphs because they were not used to reading graphs. Carers with basic computer skills had difficulty in comparing graphs as the prototype did not show two graphs in the same screen. Participants with intermediate or advanced computer skills found the graphs clear and easy to understand; however, some carers disagreed with the statement at the bottom of the graph because it was too general and ambiguous. Average scores were 4.2 (older people) and 3.6 (carers).

\section{Pair exercise}

Usefulness: participants were asked to rate the usefulness of the prototype to support the dialogue of care. In addition, the usefulness of the prototype was discussed in the semi-structured interview. All found the prototype beneficial as a tool that provided additional information of the older person's well-being. Participants said that it could be used to show key areas of well-being, to analyse changes and recognize patterns, and to monitor the older person. Average score was 4.6.

\section{Semi-structured interview}

Learnability: learning to use the prototype and understanding the graphs was a problem for some participants with basic user computer skills at the beginning of the session. When the participants became familiar with the prototype and worked together with their peers the degree of understanding graphs increased. Average scores were 4.5 (older people) and 4.7 (carers).

\section{DISCUSSION}

Some participants had problems to verbalise their thoughts in the first part. In contrast, there was a beneficial discussion between the older person and the carer in the second part, because they shared the other participant perspective. In the first part some participants had difficulties in understanding the graphs because they were not familiar with the prototype and they were not used to reading graphs. The participants found the second part enjoyable because they helped each other to understand the meaning of the graphs. The results indicated that the prototype could be used as a basis for dialogue between the older person and the carer. 


\section{CONCLUSION}

The key conclusion has been that all participants felt the interface did improve the dialogue of care between the older person and the carer. It was felt that better data promoted greater understanding and gave greater confidence in the quality and relevance of the care being given. Further work needs to be done to personalise the interface according to user preferences. There is also a need to present the normal range of each indicator (mobility, sleeping, etc.) as a reference to evaluate the grade of change.

\section{ACKNOWLEDGMENTS}

The author gratefully acknowledges the support of the Scottish Funding Council SRDG MATCH project HR04016 ("Mobilising Advanced Technologies for Care at Home") and the UK EPSRC EQUAL project GR/S29058/01 ("Supporting Independence: new products, new practices, new communities") and partners, including all participants and staff who contributed to the study. There is a special acknowledgement also for project supervisors Dr. N.A. Hine and Prof. J.L. Arnott.

\section{REFERENCES}

[1] Aldred, H., Amaral, T., Brownsell, S., Arnott, J.L., Hawley, M., Hine, N. 2005. Supporting older people through telecare. Proc. $8^{\text {th }}$ Conf. on Advancement of Assistive Technology in Europe (AAATE 05), Lille, France, 6-9 Sept., pp. 41-45.

[2] Celler, B.G., Earnshaw, W., Ilsar, E.D., Betbeder-Matibet, L., Harris, M.F., Clark, R., Hesketh, T., Lovell, N.H. 1995. Remote monitoring of health status of the elderly at home. International Journal of Bio-Medical Computing, 40 (2), pp. 147-155.

[3] Porteus, J. and Brownsell, S. 2000. Report on the Anchor Trust/BT Telecare Project. Anchor Trust, Oxon., England, UK.

[4] Strauss, A. and Corbin, J., 1998. Basics of Qualitative Research: Techniques and procedures for developing grounded theory. $2^{\text {nd }}$ edn., Sage Publications, London. 